\title{
Strontium As a Structure Modifier for Non-binary Al-Si Alloy
}

\author{
Barbora Bryksí Stunová ${ }^{1}$ \\ ${ }^{1}$ CTU in Prague, Faculty of Mechanical Engineering, Department of Manufacturing Technology, \\ Technická 4, 16607 Prague, CZech Republic
}

Correspondence to: barbora.stunova@fs.cvut.cz

\begin{abstract}
This paper presents a study of the influence on the structure of AlSi10Mg alloy when 400 ppm of strontium is added. Not only changes in the morphology of eutectic silicon, but in particular changes in the morphology of the intermetallic phases are monitored, namely phases containing iron and magnesium. The effect of strontium on structural defects, namely cavities formation, is also observed. It was found, that in non-binary system $\mathrm{Al}-\mathrm{Si}-\mathrm{Mg}$ also intermetallic phases of magnesium are affected by addition of strontium: especially phase $\mathrm{Mg}_{2} \mathrm{Si}$ changes the morphology significantly from unmodified to modified structure. Moreover, findings of other authors, that strontium has a negative effect on the level of gas porosity and on the distribution of shrinkages, are also confirmed.
\end{abstract}

Keywords: strontium, aluminum alloys, structure, structural defects.

\section{Introduction}

In the foundry industry, strontium is used as a modifier element. When it is added, eutectic crystallization is affected in order to improve the mechanical properties, especially ductility, see e.g. [1]. Findings of authors in recent years [2-6] show, that modification elements, including strontium, besides the change in morphology of eutectic silicon, also affect intermetallic phases. In this regard, interesting findings with iron have been published. Iron as a negative element creating undesirable intermetallic phases in Al-Si alloys is commonly compensated in practical applications by the addition of manganese, which helps to create intermetallic phases with a more favorable morphology (skeletal "Chinese script"). It was proven by other authors e.g. [2,5] that the morphology of iron intermetallic phases can be influenced by adding strontium. These authors usually examined binary alloys with the addition of iron, or alloys containing copper.

Other authors [1] describe the influence of strontium modification on structural defects of $\mathrm{Al}-\mathrm{Si}$ alloys, which mainly involve shrinkage and gas porosity, often a combination of the two phenomena. Generally, strontium has a negative influence on structural defects, such as cavities.

The aim of this work was to perform a complex experiment with non-binary Al-Si alloy modified by strontium, with the following goals:

- to observe the modification effect of various modification agents containing strontium in various amount

- to confirm the influence of strontium on intermetallic phases containing iron for specific nonbinary alloy
- to observe the influence of strontium on other intermetallic phases present in specific non-binary Al-Si alloy

- to confirm the influence of strontium on structural defects of a non-binary alloy

- to compare the effect of different modification agents containing strontium in various amounts on the factors mentioned above

- to compare the structural changes with the unmodified structure

- to analyze the results and formulate the theoretical consequences.

\section{Theoretical background}

The modification effect of strontium on the morphology of eutectic silicon is widely known, and is widely used in foundry practice. However, the principle is still not satisfactorily explained. One of the most accepted theories for explaining the modification principle is the IIT mechanism (Impurity Induced Twinning) e.g. [1]. However, recent studies have shown that modification changes the nucleation frequency and dynamics of eutectic grains, with associated effects on the growth rate. In unmodified commercial Al-Si alloys, a large number of eutectic grains nucleate at or near the primary aluminum dendrite tips, and eutectic aluminum forms epitaxially on the primary dendrites. On the other hand, with addition of eutectic modifiers, i.e., Sr, a dramatic decrease in the nucleation frequency of eutectic grains is observed, and the grains are nucleated independently of the primary phase at distributed centers in the interdendritic regions. The eutectic reaction in Al-Si alloys commences with the nucleation of the silicon phase, 
which is the leading phase during growth of the $\mathrm{Al}-$ Si eutectic. Aluminum phosphide (AlP) particles are very potent nuclei for eutectic silicon in commercial $\mathrm{Al}-\mathrm{Si}$ alloys, where phosphorus is commonly present as an impurity element. The addition of sodium neutralizes AlP and thus makes nucleation of eutectic silicon more difficult. More recent studies of eutectic nucleation have confirmed that AlP nucleates eutectic silicon and the large reduction in nucleation frequency of eutectic grains in Sr-modified Al-Si alloys appears to be caused by some poisoning mechanism of the potent nuclei. [2] In addition to the effect of Sr addition on the growth of eutectic $\mathrm{Si}$, recent studies have confirmed that $\mathrm{Sr}$ also significantly changes the nucleation behavior of the eutectic phases. It is proposed that the addition of Sr deactivates AlP and/or oxide bifilms as favored nucleation sites for eutectic $\mathrm{Si}$. Thus, $\mathrm{Si}$ is forced to nucleate at a lower temperature on some unknown substrate and grow as a fine, fibrous eutectic Si with high twin density. In order to confirm one of the proposed mechanisms, there is great interest in analyzing the local distribution of the modifying element within the Al-Si eutectic and at the $\mathrm{Al} / \mathrm{Si}$ eutectic interfaces. [3]

The modification may also affect the morphology of undesirable intermetallic phases, e.g. phases containing iron. As in the example in $[2,4-6]$, some modifier elements, e.g. strontium and potassium, have a positive effect on the morphology of $\beta-\mathrm{Al}_{5} \mathrm{FeSi}$, or on the conversion of this phase to the $\alpha-\mathrm{Al}_{8} \mathrm{Fe}_{2} \mathrm{Si}$ phase. The available literature does not satisfactorily describe the relationship and influence of strontium and magnesium. Some studies have identified magnesium as an element that facilitates the modification, while other studies have attributed to magnesium a negative effect on modification. However, no studies have been carried out on the effect of strontium on the morphology of intermetallic phases containing magnesium. In $\mathrm{Al}-\mathrm{Si}$ alloys, magnesium is usually found as the $\mathrm{Mg}_{2} \mathrm{Si}$ phase, but it may also be present in iron-containing phases such as the $\mathrm{FeMg}_{3} \mathrm{Si}_{6} \mathrm{Al}_{8}$ phase, or in other complex eutectics.

Modification elements may have not only a positive structural influence, but also a negative effect, manifested by an increase in porosity. One consideration is porosity due to hydrogen. Another important aspect of the modification, however, is the change in the solidification temperature range. The modification may cause changes in the model of shrinkage, and may cause gas porosity. Experiments performed by other authors have shown that total shrinkage, which is an alloy property, is not at all affected by modification. However, the way in which this shrinkage is distributed between macro-piping and microshrinkage depends strongly on whether or not the alloy is modified. Both sodium and strontium cause a significant diminution of the primary pipe and an increase in the amount of microporosity. In other words, shrinkage is redistributed when modification occurs. [1]

\section{Experimental}

Non-binary EN AC-43100 (AlSi10Mg) alloy was chosen for the experiment (for chemical composition, see tab. 1). The batch consisted only of alloy ingots, with no recycled material. The melt was neither refined nor degassed. The samples were cast in a green sand molding mixture, with 4 casting samples in one mold. The reference samples were cast without modification. $400 \mathrm{ppm}$ of strontium was added to the modified samples in the form of the following five modification agents: AlSr3.5, AlSr5, AlSr10 prealloys - all wrought, AlSr10 cast pre-alloy and pure strontium. Samples for metallography were taken from the castings, and the chemical composition of the samples was measured (Table 2).

Table 1: Standard prescribed chemical composition of experimental alloy AlSi10Mg

\begin{tabular}{|c|c|c|c|c|c|c|c|c|c|}
\hline alloy/element & $\mathrm{Si}$ & $\mathrm{Fe}$ & $\mathrm{Cu}$ & $\mathrm{Mn}$ & $\mathrm{Mg}$ & $\mathrm{Ni}$ & $\mathrm{Zn}$ & $\mathrm{Ti}$ & $\mathrm{Al}$ \\
\hline $\begin{array}{c}\text { EN AC-43100 } \\
\text { (AlSi10Mg) }\end{array}$ & $9-11$ & 0.55 & 0.10 & 0.45 & $0.20-0.45$ & 0.05 & 0.10 & 0.15 & remainder \\
\hline
\end{tabular}

Table 2: Resultant measured chemical composition of casting samples

\begin{tabular}{|l|c|c|c|c|c|r|c|c|c|c|c|}
\hline agent/element & $\mathrm{Si}$ & $\mathrm{Fe}$ & $\mathrm{Cu}$ & $\mathrm{Mn}$ & $\mathrm{Mg}$ & $\mathrm{Ni}$ & $\mathrm{Zn}$ & $\mathrm{Ti}$ & $\mathrm{Sr}$ & $\mathrm{P}$ & $\mathrm{Al}$ \\
\hline unmodified & 10.304 & 0.304 & 0.032 & 0.230 & 0.398 & 0.005 & 0.078 & 0.055 & 0 & 0.006 & 88.496 \\
\hline AlSr3.5 & 10.337 & 0.311 & 0.024 & 0.153 & 0.362 & 0.006 & 0.098 & 0.076 & 0.037 & 0.006 & 88.511 \\
\hline AlSr5 & 10.627 & 0.327 & 0.022 & 0.156 & 0.332 & 0.006 & 0.093 & 0.077 & 0.044 & 0.006 & 88.225 \\
\hline cast AlSr10 & 10.177 & 0.254 & 0.040 & 0.320 & 0.402 & 0.002 & 0.037 & 0.024 & 0.031 & 0.006 & 88.613 \\
\hline wrought AlSr10 & 10.247 & 0.246 & 0.041 & 0.318 & 0.412 & $<0.002$ & 0.035 & 0.024 & 0.044 & 0.006 & 88.532 \\
\hline pure Sr & 10.689 & 0.259 & 0.025 & 0.163 & 0.337 & 0.005 & 0.086 & 0.071 & 0.018 & 0.006 & 88.259 \\
\hline
\end{tabular}




\section{Results}

The metallography provided some interesting findings. On closer examination, the eutectic grain boundary areas show coarse eutectic silicon. In addition, these sites contain coarse intermetallic phases, in particular iron, iron and manganese and magnesium phases (Figure 1).

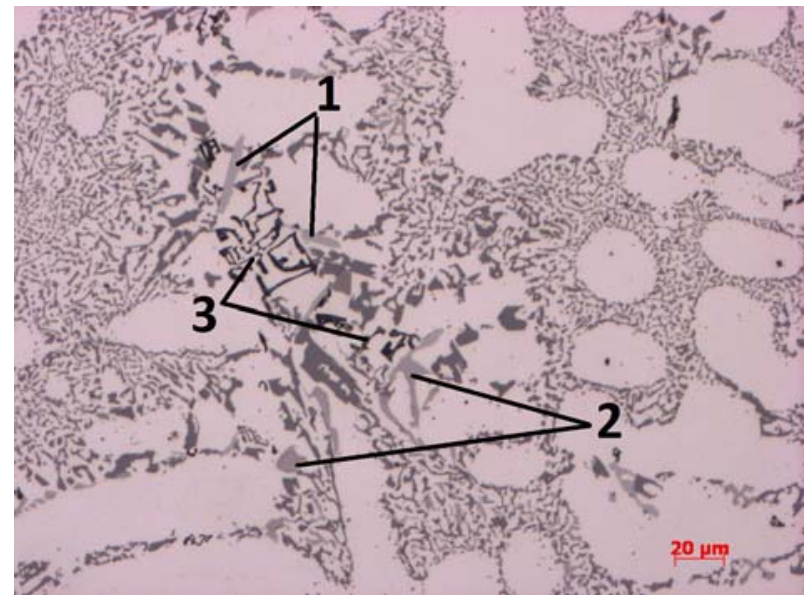

Figure 1: AlSr3.5 modified sample - characteristic intermetallic phases at grain boundaries, $200 \times, 1-$ phase of iron, probably $\beta-\mathrm{Al}_{5} \mathrm{FeSi}, 2-$ phase of iron and manganese, probably $\mathrm{Al}_{15}(\mathrm{FeMn})_{3} \mathrm{Si}_{2}, 3-$ phase of magnesium $\mathrm{Mg}_{2} \mathrm{Si}$

A spectral analysis of selected phases was performed to confirm the assumptions presented above about the composition of the intermetallic phases at the grain boundaries. It turned out that magnesium is also present in the phases that were assumed to be of $\mathrm{Al}(\mathrm{FeMn}) \mathrm{Si}$ type. Figure 2 shows a detail of connected intermetallic phases. Position Spectrum 1 was defined as the phase where, in addition to aluminum and silicon, chromium also occurs, and especially manganese and iron in the order of units to tens of percentage points. In addition to what is indicated above, Spectrum 3 shows a content of 1.32 wt. \% of magnesium. Besides the aluminum and silicon content, positions 2 and 4 also have around $6 \mathrm{wt}$. $\%$ magnesium, 4 wt. \% iron, but very little or no manganese content.

Similarly, Figure 3 shows a phase containing magnesium (12\%), iron (4.3\%) and manganese (0.83\%) as position 1. Position 2 is the eutectic silicon phase. Position 3 is rich in magnesium and silicon, while the morphology may be considered as an $\mathrm{Mg}_{2} \mathrm{Si}$ phase, confirming the original assumption.

When comparing the different structures obtained by the modifying agents, various morphologies of the various intermetallic phases and cavity structural defects can be observed.

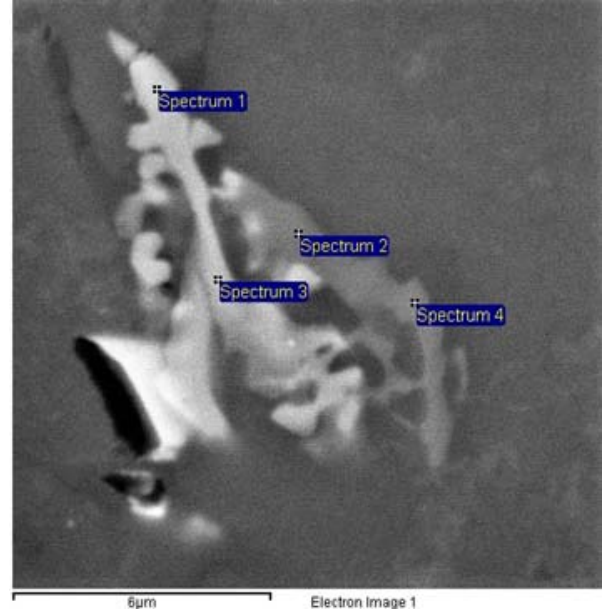

Figure 2: Detail of intermetallic phases of modified structure from electron microscopy and spectral analysis

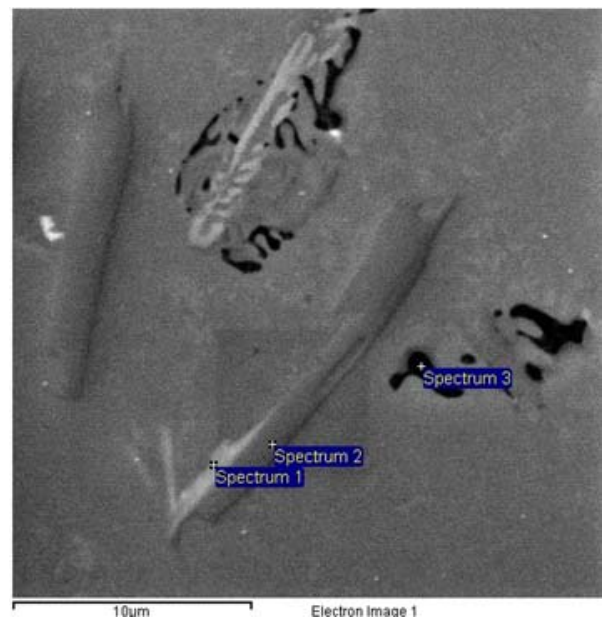

Figure 3: Detail of intermetallic phases of modified structure from electron microscopy and spectral analysis

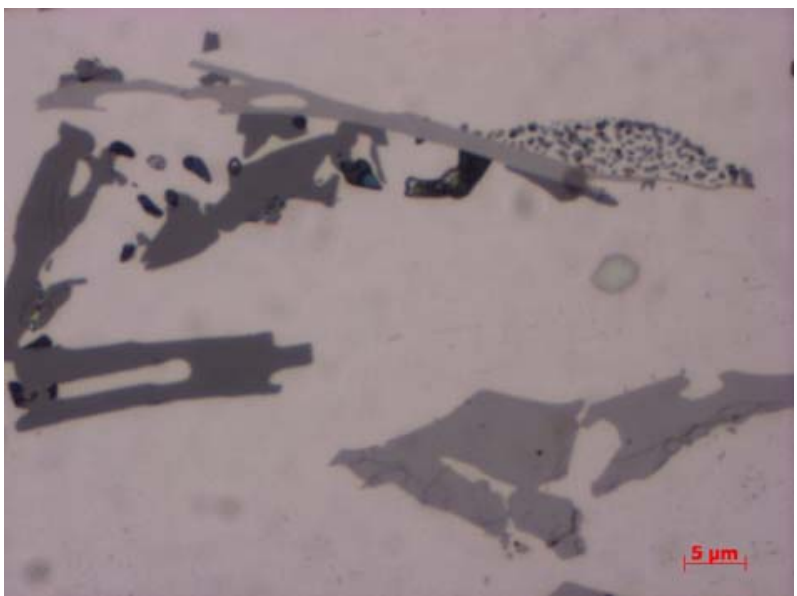

Figure 4: Unmodified structure, mag. $1000 \times$

An unmodified structure (Figure 4) contains the primary dendrites of the solid solution and 
the coarse eutectic, intermetallic phases of iron, which are of acicular to skeletal character, while the branches of these particles are quite massive. Occasionally there are skeletal particles of magnesium phase $\mathrm{Mg}_{2} \mathrm{Si}$, always tied to the eutectic silicon or iron phase. The magnesium phases are often fragmented. There are "lace" formations containing various intermetallics (Figure 4). According to color, these mixed phases can be considered as phases of iron and magnesium. An unmodified structure does not contain significant amount of shrinkage porosity.

In the structure modified by agent AlSr3.5, coarse acicular to flat formations of iron and manganese phases occur at the grain boundaries, and there are skeletal magnesium formations, which are always bound to the iron phase and/or to the modified (fibrous to acicular closer to the grain boundaries) eutectic silicon (Figure 5). Cavities are present, usually in combination of interdendritic shrinkage and gas porosity.

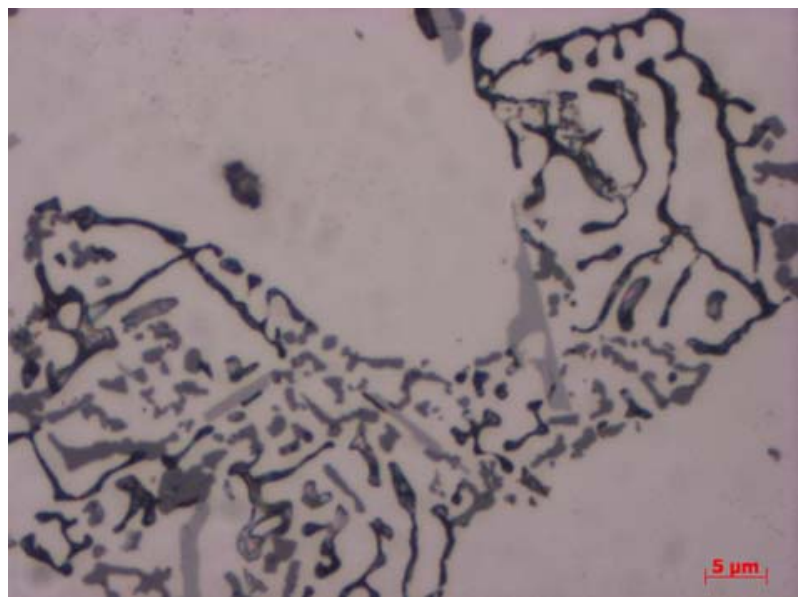

Figure 5: Structure modified by AlSr3.5, mag. $1000 \times$

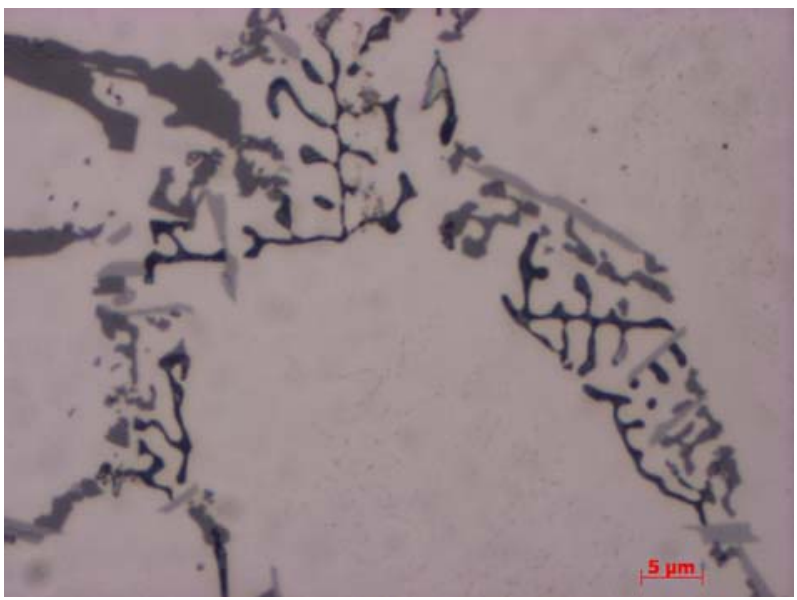

Figure 6: Modified by AlSr5, mag. 1000×
In the structure modified by agent AlSr5 (Figure 6 ), acicular to rough flat formations of iron and manganese phases and skeletal magnesium formations occur. There are large numbers of cavities in all samples, mostly interdendritic shrinkage porosity combined with gas.

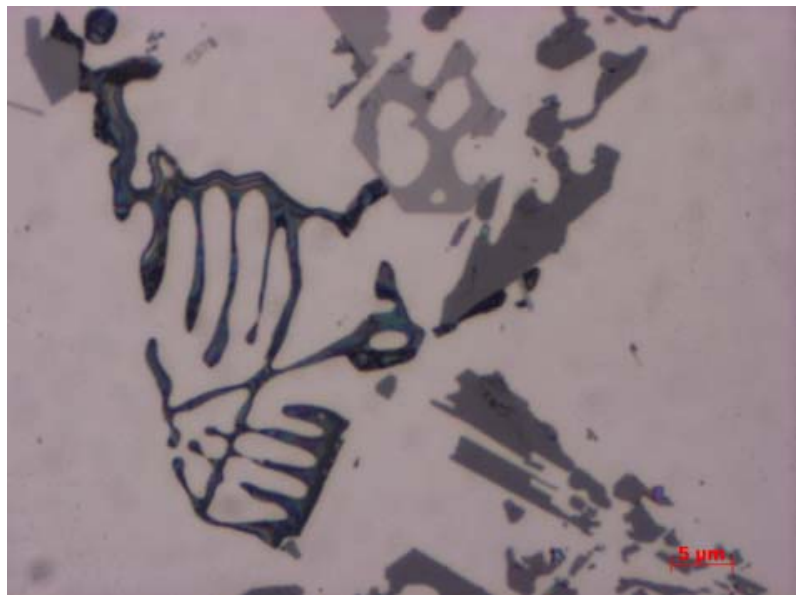

Figure 7: Modified by cast AlSr10 agent, mag. $1000 \times$

The structure modified by cast agent AlSr10 shows rough acicular to skeletal phases of iron and manganese, and skeletal magnesium phase formations, which are always bound to the iron phases (Figure 7). Finer phases of iron interfere with the eutectic. Interdendritic shrinkages combined with gas bubbles appear in the structure.

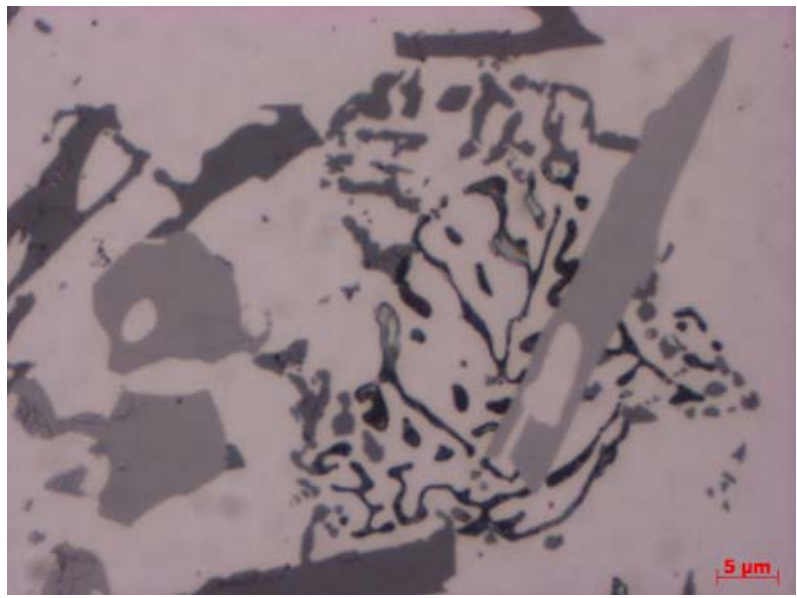

Figure 8: Modified by wrought AlSr10 agent, mag. $1000 \times$

In a structure modified by wrought agent AlSr10 (Figures 8, 10, 11), coarse acicular formations to skeletal phases of iron, manganese and skeletal magnesium phases occur. These magnesium 
phases are always bound to the iron phases. Iron phases interfere with eutectic silicon. Coarse iron formations are rougher than structures modified by cast agent AlSr10. Cavities are present, usually a combination of interdendritic shrinkage and gas porosity.

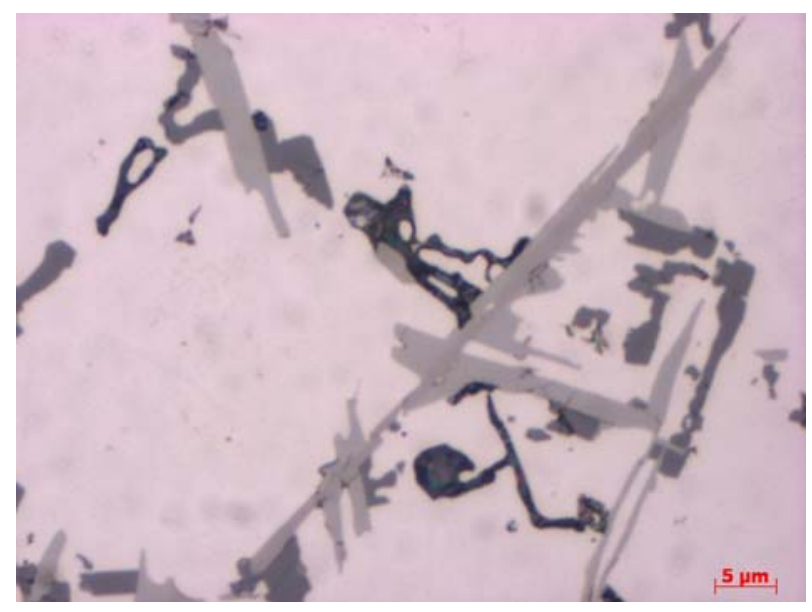

Figure 9: Modified by pure Sr, mag. 1000×

Pure Sr affected the structure (Figure 9) in such a way that there are coarse to flat formations of iron phases which interfere with the eutectic. They are often parallel. Magnesium phases are gentle, always tied to different phases. There are also small round to teardrop-shaped formations of mixed phases. Combined porosity is present.

\section{Discussion of results}

The expected result of modification - finer morphology of eutectic silicon - was obtained by all modification agents, even by pure strontium, the residual content of which in the sample is lower than the other modification agents (see Table 2). This lower measured amount in the cast sample can be explained by the worse dissolution conditions when strontium in pure metal form is added to the melt. The residual content of strontium in samples modified by pre-alloys with aluminum (AlSr3.5, AlSr5, wrought AlSr10 and cast AlSr10) is comparable, close to an added amount of $400 \mathrm{ppm}$. Two agents (AlSr5 and wrought AlSr10) reached a higher residual strontium value than the added amount of $400 \mathrm{ppm}$. This phenomenon can be explained by higher local concentration of strontium.

Figures 4 to 9 show the structures of the unmodified sample and samples modified by various modification agents based on strontium. In particular, details of intermetallic phases, which are characteristic for AlSi10Mg alloy, are shown. Namely there are phases of iron and magnesium. Other elements, listed in Tables 1 or 2, are dissolved in solid solution or they are contained in complex intermetallic phases. For example, manganese is usually a part of the intermetallic phases of iron (characteristic skeleton phases also called Chinese script, e.g. in Figure 2).

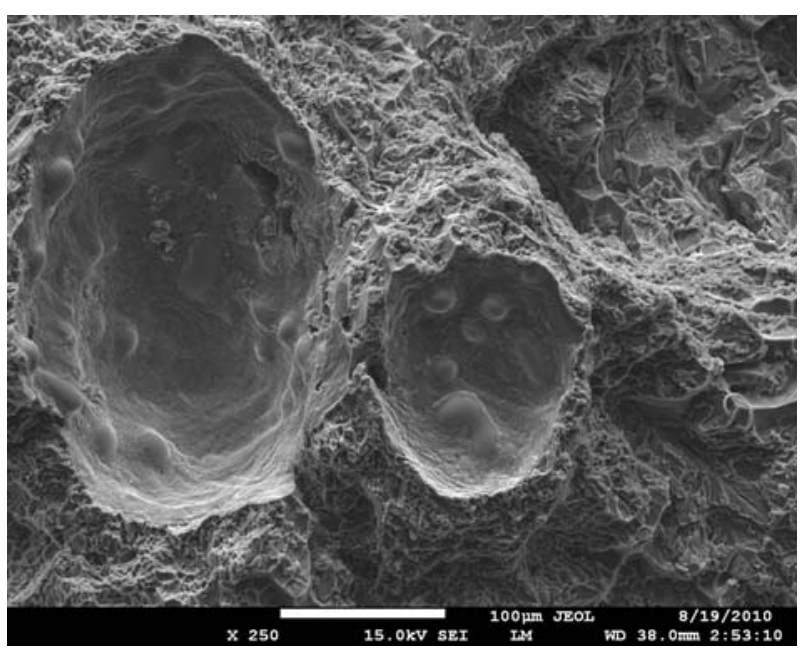

Figure 10: Hydrogen bubbles on the fracture area, both samples are modified by the wrought AlSr10 agent

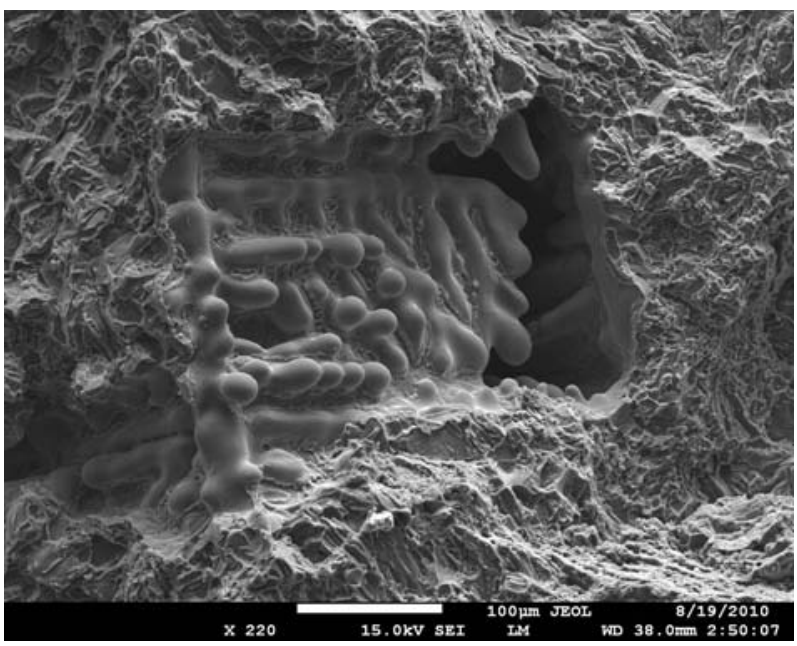

Figure 11: Dendritic arms and interdendritic shrinkage on the fracture area, both samples are modified by the wrought AlSr10 agent

Unmodified structures, especially characteristic intermetallic phases (Figure 4), have a different morphology from modified structures. The most significant difference can be observed in the morphology of magnesium phase $\mathrm{Mg}_{2} \mathrm{Si}$ (black color particles in Figure 4, or skeletal shapes in other pictures). The sample obtained by pure strontium modifying has the morphology of the $\mathrm{Mg}_{2} \mathrm{Si}$ phases closest to the unmodified structures. This similarity is also related to the residual strontium content in this sample (Table 2). The iron phases also have a different morphol- 
ogy in the unmodified sample and in the structure obtained by modification, where these phases are more skeletal or flat, and not so coarse. The only exception is again the structure modified by pure strontium, which is similar to the unmodified structure, and also contains "lace" or teardrop-shaped formations of mixed phases. The specific phenomenon of non-binary alloys can be observed, e.g. the AlSi10Mg alloy that the intermetallic phases interfere with each other and with eutectic silicon on the eutectic grain boundaries. Magnesium phase $\mathrm{Mg}_{2} \mathrm{Si}$ in particular, is always bound to phases of iron.

Structural defects, especially cavities, were also observed in the obtained structures. It can be stated that the unmodified structure contains less porosity than the modified structure. Even the structure modified by pure strontium contains more cavities of combined porosity.

\section{Conclusions}

The following conclusions can be drawn based on the presented experiments:

- All structures (apart from the unmodified structures) were modified, and the morphology of eutectic silicon was changed from coarse to finer acicular or fibrous eutectic silicon. Modification was achieved by all the modification agents based on strontium that were used.

- It was observed that the structure of a nonbinary alloy such as AlSi10Mg can also be influenced by strontium (in addition to the modification effect): the coarse acicular morphology of iron based intermetallic phases changes to a flatter shape or even to a skeletal shape when strontium is added. This finding confirms and complements findings of other authors (e.g. $[2,4-6]$ ).

- It was found that in the non-binary system Al$\mathrm{Si}-\mathrm{Mg}$ intermetallic phases of magnesium are also affected by the addition of strontium: especially phase $\mathrm{Mg}_{2} \mathrm{Si}$ changes significantly in morphology from an unmodified structure to a modified structure. The change can be described as a transformation from a fragmented phase to skeletal formations.

- It was confirmed that the addition of strontium influences structural defects such as cavities. Modified structures show a greater degree of porosity, which can generally be referred to as combined porosity (gas + shrinkage).

- It was confirmed that various modification agents based on strontium, with various amounts of strontium in the pre-alloy, behave differently with different effects. The effect on the morphology and the mechanical properties of eutectic silicon has been published e.g. in [8-10]. The effect on the morphology of intermetallic phases is described above. For an exact description of the influence for each individual pre-alloy, it will be necessary to make further observations with a qualitative and quantitative evaluation of the morphology of the intermetallic phases.

- There are significant differences between unmodified structures and modified structures (irrespective of the modification agent): in addition to the change in eutectic silicon morphology, changes in the morphology of intermetallic phases, e.g. phases based on iron and magnesium, are observed (see above).

- The changes in the morphology of the intermetallic phases influence the mechanical properties of the alloy. The work has shown that strontium affects the morphology of intermetallic phase $\mathrm{Mg}_{2} \mathrm{Si}$. This phase can influence not only tensile strength or ductility, but also the process of heat treatment, mainly hardening of $\mathrm{Al}$ alloys, which comprises solution annealing and aging. It can be assumed that if the hardening phase $\mathrm{Mg}_{2} \mathrm{Si}$ has a suitable and controllable morphology, with uniform distribution in the volume of the casting, the annealing could be shortened or the effect of heat treatment could be greater. Further studies are needed, and more experiments need to be performed, to verify this assumption.

\section{Acknowledgement}

The work presented in this paper was supported by project SGS OHK2-038/10.

\section{References}

[1] Gruzleski, J. E., Closset, B. E.: The Treatment of Liquid Aluminium — Silicon Alloys. Des Plaines: American Foundrymen's Society, Inc., 1999. 256 pp.

[2] Cho, Y. H., et al.: Effect of Strontium and Phosphorus on Eutectic Al-Si Nucleation and Formation of $\beta-\mathrm{Al}_{5} \mathrm{FeSi}$ in Hypoeutectic Al-Si Foundry Alloys. Metallurgical and Materials Transactions. 2008, Vol. 39, No. 10, p. 2435-2448. http://www.springerlink.com/content/ 6883p01714hp2774/

DOI: $10.1007 / \mathrm{s} 11661-008-9580-8$.

[3] Timpel, M., et al.: Microstructural investigation of Sr-modified Al-15 wt \% Si alloys in the range from micrometer to atomic scale. Ultramicroscopy. 2011, Vol. 111, Issue 6, p. 695-700. ISSN 0304-3991. 
[4] Haro-Rodríguez, S., et al.: On influence of Ti and $\mathrm{Sr}$ on microstructure, mechanical properties and quality index of cast eutectic $\mathrm{Al}-\mathrm{Si}-\mathrm{Mg}$ alloy. Materials \& Design. 2011, 32, p. 1865-1871. ISSN 0261-3069.

[5] Ashtari, P., Tezuka, H., Sato, T.: Modification of Fe-containing intermetallic compounds by K addition to Fe-rich AA319 aluminum alloys. ScriptaMaterialia. 2005, 53, p. 937-942. ISSN 1359-6462.

[6] Shabestari, S. G., Ghodtat, S.: Assessment of modification and formation of intermetallic compounds in aluminum alloy using thermal analysis. Materials Science \& Engineering A. 2007, A 467, p. 150-158. ISSN 0921-5093.

[7] Li, Z., et al.: Parameters controlling the performance of AA319-type alloys: Part I. Tensile properties. Materials Science $\&$ Engineering A. 2004, 367, p. 96-110. ISSN 0921-5093.

[8] Bryksí Stunová, B.: Study of modification effect of different types of agents based on strontium in Al-Si alloys. CTU in Prague, Faculty of Mechanical Engineering, 2011. Disertation. 148 pp.

[9] Bryksí Stunová, B.: Studium modifikačního účinku stroncia z hlediska času po modifikaci a koncentrace v předslitině. In 48. Slévárenské dny - abstracts proceedings. Brno : Česká slévárenská společnost, 2011, p. 34. ISBN 978-80-02-02337-1.

[10] Stunová, B., Luňák, M.: Al(4)sr particles size and morphology influence on modification of $\mathrm{Al}-\mathrm{Si}$ alloys. In 19th International Conference on Metallurgy and Materials. Ostrava : Tanger ltd, 2010, p. 642-646. ISBN 978-80-87294-17-8. WOS: 000286658700109. 